\title{
Beyond Translating French into English: Experiences of a Non- Native Translator
}

\author{
Harriet K. Namukwaya \\ University of Alberta
}

\subsection{Introduction}

The Institute of Languages at Makerere University (MIL) offers a variety of services to a wide clientele, including Ugandan nationals as well as foreigners in the East African Region. These foreigners include diplomats from European and African countries who do not speak English as their first or second language, businessmen from neighboring francophone countries, for instance, the Democratic Republic of Congo as well as students from other countries such as Sudan, Rwanda, Burundi, Tanzania and Kenya among others. The services offered include teaching language and communication skills within the framework of short courses and degree courses, and undertaking editorial work, translation and interpretation in different areas of specialization. Translation and interpretation services are usually needed in the area of French, which is why the focus in this paper is on the translation from French into English.

Uganda shares borders with three francophone countries: the Democratic Republic of Congo (DRC), Rwanda and Burundi. Over the years, students from these countries have been coming to Uganda to pursue university education. As a condition of admission to Ugandan universities or any other tertiary institutions in Uganda, they must have their academic documents translated into English, the official language of Uganda. This is done to verify the academic level of those students. In the same vein, some francophone teachers and businessmen come to Uganda with the aim of identifying greener pastures, i.e. in the hope of obtaining opportunities to teach French at school and university levels. To be recognized as qualified teachers in the Ugandan education system and to be included on the government payroll, they are required to have their academic documents translated into English. This is usually done to assess their education level and qualifications and to establish whether they are fit to teach in the Ugandan education system. The need for translation of these academic documents has, in the long run, created a demand for translators in Uganda. 
The data used in this study was collected from six Ugandan instructors of French, all aged above thirty. They had been translators for more than five years. Within the context of the study, this implies that the selected instructors had had enough experience and competence in undertaking translation activities. However, five of them did not consider themselves to be professionally trained translators. These instructors acquired the experience and competence in translation either on the job (the self-trained translators) whose entry point into translation was their good knowledge of the French language and culture, or they were initiated into translation by their colleagues. The study focused on the types of documents translated, how the selected French language teachers became translators, the challenges they encountered in the process of translating particular documents, the causes of the challenges encountered and the strategies they used to overcome the specific challenges they encountered.

The data used in this study was collected by means of a questionnaire and an interview. The questionnaire was administered specifically to participants who did not have enough time to spare for an interview. The questionnaire and the interview addressed the same issues for purposes of uniformity.

\subsection{Findings and Discussion}

\subsection{Definition of Translation}

There are various interpretations or definitions of translation. Cary (qtd. in Ballard1987), defines translation as an operation whose objective is to establish equivalences between two texts written in two different languages. He adds that equivalences should be understood in the context of the two texts as well as the relationship that exists between the cultures of the two texts. Translation can also be defined as the use of verbal signs to understand the verbal signs of another language. Translation usually refers to the transfer of written verbal codes between languages (Lustig \& Koester 175). Translation involves transfer of "meaning" contained in one set of language signs into another set of language signs through competent use of a dictionary and grammar. The whole process also involves a set of extra-linguistic criteria. Mounin perceives "translation as a series of operations whose starting point and end product are significations and function within a given culture" (qtd. in Bassnett 15). The working definition for this paper is that given by the participants in the study. They defined translation as "the rendering of meaning from one language (the source language) into another language (the target language)." According to them, translation involves reading or listening attentively as well as 
understanding and rendering the message in the target language as faithfully as it is signified in the source language.

\subsection{Type of translation}

In his article "On linguistic aspects of translation" Jakobson distinguishes three types of translation: Intralingual translation or rewording, which simply refers to an interpretation of verbal signs by means of other signs in the same language; interlingual translation or translation proper, which signifies an interpretation of verbal signs by means of some other language; and intersemiotic translation or transmutation, which refers to an interpretation of verbal signs by means of a nonverbal sign system(114). This paper specifically focused on the interlingual translation that is standard practice at MIL. This kind of translation involves the interpretation of written documents from French (the source language) into English (the target language). Interpretation simply refers to providing both the direct and inferred meaning of the source text to the user of the translated text.

\subsection{How Foreign Language Teachers become translators at Makerere Institute of} Languages.

To my knowledge, foreign language teachers become translators in different ways. This is not only characteristic of teachers of French at the Institute of Languages but also of teachers of German, Arabic, Swahili and local languages like Lugbara, Runyakitara and Luganda among others. The results of the study show that the instructors of French become translators for the following reasons and in the following ways:

\section{a) Need to translate documents}

As already pointed out in the introduction, Ugandan universities usually admit students from the francophone countries with which it shares borders. In order to be admitted to the Ugandan universities or other tertiary institutions in Uganda, such students usually have to have their academic documents translated into English, the official language of Uganda. Additionally, Uganda hosts international conferences and symposia which bring together delegates from anglophone and francophone countries. In order to facilitate communication among delegates and comprehension of the conference proceedings and communications for both parties, translation and interpretation services are needed. In some cases, doctors from other countries, for instance Rwanda, refer their patients to Mulago Hospital in Uganda with referral and treatment notes written in French. The need for translation of academic documents, 
conference papers and proceedings, and referral and treatment notes has, in the long run, created a demand for translators in Uganda. Consequently, the teachers of French at MIL embarked on the translation of such documents from French into English. Given the fact that there is no well-established body offering translation and interpretation services in Uganda, the Ministry of Education and other government bodies requested MIL to provide such services to those who needed them. The current translators at the Institute are not all professionally trained translators. Their ability to translate such documents is based on the fact that they have knowledge of the French language and have acquired experience by interpreting at conferences and translating various types of documents.

b) Encouragement by colleagues

Due to the increasing demand for translation services and the limited number of translators at MIL, the experienced instructors of French thought it wise to initiate junior colleagues into the translation exercise. The "initiation" was done by giving documents to juniors to translate on the basis of samples of already translated documents similar to those that were to be translated. The junior colleagues were also encouraged to make use of bilingual dictionaries to look up new words in the process of translation. After the translation was completed, it was then returned to the mentor for a second look. This was done repeatedly and consistently, ultimately enabling the junior colleagues to become translators. In fact, four participants in the study stated that they were "trained" to be translators by their senior colleagues. However, this kind of "training" is no longer done due to the fact that a large number of instructors have experience in translating various documents and currently, there is no new junior staff to "train" in the area of translation.

c) Need to earn money

Translation at MIL is more of a business undertaking than a systematic training in translation. Translators are paid for their work. The remuneration does not only motivate the translators to work better and in a more efficient way but also attracts other language teachers to translation. The translation activities at MIL tend to be based on the premise that competence in translation requires one to have only linguistic knowledge. It can be argued that neither having sufficient linguistic knowledge of languages nor being efficiently bilingual is enough to become a professional translator. In fact, Delisle states clearly that "linguistic competence is a necessary condition, but not yet sufficient for the professional practice of translation" (28).

\subsection{Types of documents translated}


Various types of documents are usually translated at MIL. These include:

a) Legal and court documents: summonses and complaints, judicial proceedings, power of attorney, employment contracts, marriage certificates, birth and death certificates as well as certificates of good conduct

b) Academic documents: school reports, certificates, testimonials and transcripts.

c) Medical: laboratory reports, treatment notes, and referrals

d) Commercial: exportation declaration forms, car registration certificates and log books

e) Conference papers and proceedings

\subsection{Challenges encountered}

The responses in the study show that the non-native translators at MIL encounter various challenges in the process of translating documents from French into English.

a) Limited language competence in the source and target languages

Good translation practice requires that the translator has good mastery of both the source language and the target language. The mastery is not limited to being competent in linguistic knowledge of the source and target languages but also in the cultural knowledge embedded in the two languages. However, at MIL, it is believed that every qualified language teacher is qualified to be(come) a competent translator. The translation skill is very different from the pedagogical skill. Translation deals with the transfer of meaning from one language to another whereas pedagogy is concerned with the methods that facilitate learning. In other words, being a competent language teacher or being fluent in two languages may not necessarily come with the ability to translate. However, due to the increasing demand from clients to have different types of documents translated, translation activities are being undertaken by teachers of French who may have limited or no knowledge of the content or areas of specialization in the documents. The limited knowledge of the source and target languages in the specific subject areas is one of the major limitations which cause mistranslations.

In fact, limited vocabulary in both the source and target languages may impede the non-native translator's ability to identify the adequate equivalence for a word in the target language. Sometimes, the challenge lies in establishing equivalence in the grammatical or 
syntactical rule systems of two languages (French and English). The following examples serve to illustrate this challenge:

i. Ce certificat est délivré à qui de droit. This phrase was translated as "This certificate is issued To Whom It May Concern."

The translated version is grammatically or syntactically correct but it does not really reflect the limited or implied meaning in the statement, which is "The certificate is to serve and avail when necessary."

\section{ii. "Radié pour Nigéria": Translated as "rayed for Nigeria."}

Here, the translator lacked sufficient knowledge about the subject matter and the context in which the term "Radie" was used and instead translated it literally, which led to the loss of the intended meaning of the original phrase (posted to Nigeria). Translation involves far more than replacement of lexical and grammatical items between languages (Bassnett 25). The translation process may involve discarding the basic linguistic elements of the source language text so as to achieve the functional equivalence of elements in both the original text and the translation product (Bassnett 25).

b) Technicality of documents

As already mentioned in Section 2.4 above, the translators at MIL engage in the translation of legal, medical and conference papers and documents. In most cases, these documents fall within a certain area of specialization, about which the translator may have limited knowledge. This implies that the translator depends on specialized dictionaries as the only source of information. In the French section, there are hardly any specialized dictionaries at the moment. Online resources would be a better alternative, but unfortunately, the Internet connection is unpredictable at Makerere University, which makes accessibility and reliance on such resources impossible. Additionally, some translators at MIL are unaware of the existence of specialized online resources in translation, so they rely only on the available dictionaries. The few dictionaries that are available are in the areas of economics, commerce and finance. Due to the limited number of dictionaries in the French section, some French language teachers/translators have decided to buy their own specialized dictionaries. The lack of knowledge of the subject matter, for example, the medical or legal jargon, proper training in translation as well as the absence of specialized dictionaries in those particular areas render the translation of such documents very difficult and may sometimes lead to mistranslations. 
Working with a limited number of specialized dictionaries and lack of access to specialized online resources make the translation of technical documents challenging. Specialized dictionaries are only available in the areas of economics, finance and law and are lacking in the areas of medicine, health, environment, and politics among others. The translators usually rely on archives of similar already translated documents, or parallel texts, or sometimes consult specialists, when such specialists are available. The lack of specialized dictionaries and the lack of easy accessibility to online resources consequently cause delays in translating difficult texts in specialized areas.

\section{c) Polysemy and false friends}

This simply refers to words that have more than one equivalence in the target language or words that look similar in spelling in the source and target languages but have different cognates. Such words or expressions make the choice of equivalences or words in the target language very difficult. In the following example, the translator translated the statement word for word, which consequently led to an inaccurate translation and thus a loss of meaning in the target text.

"Son attitude civique n'a donné à aucun reproche": His civic attitude is without reproach.

In this example, it can be noted that the translation does not reflect the exact meaning or the intended meaning in the statement (He has a clean criminal record). Translating whole sentences into the target language as opposed to isolated words and translating in context would have helped in this case to convey the intended meaning. While some translators make an effort to remain faithful to the meaning of the original text, other translators tend to focus on finding equivalents of individual words. Given that language represents a "socially situated cultural form" (Saville-Troike qtd. in Crane et al 43) rather than a neutral means of communication, any act of translation of academic or legal terms requires a healthy dose of sensitivity to the specific social, political and cultural meanings embedded in both the languages used (Booth, 1993). This can be further illustrated in the examples below:

\section{"L'extrait est demande": Translated as "The record is asked for."}

In the above example, the translator put more emphasis on translating individual words instead of focusing on the meaning in the context in which the sentence was used ("The record is applied for").In other words, the meaning was derived from the surface structure of the sentence. The surface structure simply refers to the isolated words and syntax but not to the content and context of the source text. Mitchell argues that 
translators tend to misdirect their attention towards words (90). In so doing, they fail to follow the thread of the argument or narrative. Smith argues that "meaning is derived from the deep structure of what we read, not the surface structure. He adds that meaning comprises more than the words: "translators do not need to decipher every word in order to reach the meaning; on the contrary, they rely on the meaning to determine what the next words will be"(qtd. in Mitchell 90). In most cases, translators at MIL tend not to read the source text but start the translation right away, which may cause them to only focus on the words instead of the content and context of the text. This may lead to mistranslations as illustrated by the examples above.

In addition, in the following example, the translator looked exclusively for the equivalents of individual words, which led to unnecessary repetition as well as loss of meaning.

"certificat de bonne conduite, vie et mours et de civisme" which was translated as "certificate of good conduct, life, morals and civism" instead of "certificate of good conduct," which would best reflect the intended meaning. In translating such phrases, it is the function that is taken up and not the words themselves, and the translation process involves a decision to substitute linguistic elements in the target language (Bassnett 21).

\section{d) Culture-bound words}

The same language may be used by various language communities but each community may attach a particular meaning to a particular word. This is quite evident in the documents brought for translation at MIL. This fact poses a challenge to non-native speakers who have limited cultural knowledge in the source language (SL) and the target language (TL). This means that some translation tasks require not only linguistic knowledge but also an extensive awareness of cultural nuances in both behaviours and languages. For example, the word "Licence" in Belgian French and Congolese French (Democratic Republic of Congo) refers to a Master's Degree whereas in France, it refers to an undergraduate degree. If the translator does not know the context and is not aware of the cultural nuances of the source text, $\mathrm{s} / \mathrm{he}$ is bound to mistranslate the word. In addition, some words or expressions do not appear in the dictionaries, which makes the translation process difficult for a non-native translator who, in most cases, relies on the dictionary. Non-equivalence of certain concepts in English and French is another important issue with linguistic implications (Lustig\& Koester 176). For example, in the Congolese education system the term "graduat" is used, which does not exist in the dictionaries usually used by translators at MIL. The term "graduat" simply means 
undergraduate degree in Congolese French. Concepts unfamiliar to the non-native translator's culture or English culture constitute challenges when it comes to translating in a manner that is culturally and linguistically relevant and acceptable according to the expected standards. One of the participants in the study mentioned that:

Sometimes the language of the source text is culturally conditioned or culturespecific and does not conform to the standard French. Some words do not exist in the dictionaries.

Casanave argues that the translation of academic concepts originating from different language contexts and the negotiation of the (partly) different meanings represent a difficult and challenging "balancing act"(198). This is indeed true in the case of translating academic documents from French into English at MIL as the above examples clearly illustrate. Not only do culture-bound words pose a problem in the translation of academic documents, but translators translating legal documents/texts from French into English are also faced with specific challenges. These arise from the fact that the legal jargon (legal terms or concepts) used in the source text may have no equivalents in the target language. The legal language used in different legal institutions, judicial systems and court procedures varies depending on the country and context. Translators involved in the translation of legal documents should specifically be aware of "false friends" or expressions that are nonexistent in the target language. The example below illustrates this point:

"Monsieur Lubango est de bonne conduite, vie et moeurs et que son attitude civique n'a donné lieu à aucun reproche" (Congolese French), which was translated as "Mr. Lubango has exbibited good conduct, life and behaviour and his/her civic attitude is without reproach" (This should have been: Mr. Lubango is of good conduct. He has never been convicted of any criminal offence or come to adverse police notice.)

If translators are not aware of such differences in the wording of legal documents in different legal systems, their word for word translation can be misleading.

Karamanian also argues that in translation, translators do not just deal with words written in a certain time, space and sociopolitical situation; most importantly it is the cultural aspect of the text that translators should take into account (n.p.). One of the participants in the interviews carried out at MIL acknowledged that:

As a non-native speaker, there are a lot of terms, expressions, knowledge of the history and culture that one does not have. 
Limited knowledge about the history and culture of the source or target language can lead to translation difficulties.

e) Insufficient time to concentrate on the translation work

The translation activities at MIL are undertaken in an academic context, in which teaching activities are expected to be given priority over translation. Consequently the teachers of French, who are assigned language classes to teach, are sometimes unable to meet the deadlines set by the commissioning agent. Fully-engaged language teachers often don't have the time required to deliver good translation results. A translator needs adequate time to study the source text, to undertake research about ambiguous words, to select the adequate equivalences and to consult colleagues or native speakers whenever the need arises, especially in the case of words that do not appear in dictionaries. The responses given by participants indicate that the time allocated to translation work is in most cases insufficient. Working under such circumstances does not enable translators to focus on the fidelity or details of the source text nor the readability in the target language but rather on how fast they can finish the translation assignment. This method of work leads to errors and sometimes also to mediocre results in the submitted work. In fact, when the work is returned due to errors, the revisions consume more time than it would have taken if the translator had had more time initially.

The consequence of doing the translation work hurriedly is illustrated in the following examples:

i. Signature de l'élève- Student sign (student's signature)

ii. Éducation professionnelle- vocation education (vocational education)

iii. L'élève passe à la classe supérieure- The student promoted (the student is promoted to the next grade.

\section{iv. Diplômé avec 60\% - certificate with $60 \%$ (passed with 60\%)}

Working under tight deadlines also tends to prevent the translators from taking time to check their work or proofread the finished work, search for synonymous/ambiguous words or new words or run a spell-check before the translated work is submitted. As a result of doing the work so hurriedly, some translators submit translations which are below the expected standard. In fact, Mitchell argues that "the task of translating is like an onion: the layers can be peeled away until you reach the heart (91). Removing the 
non-essential layers is another way of reaching the deep structure. The author is one layer: s/he may well have written on someone else's instructions: the commissioning agent is another layer, and the commercial transaction between the translator and the agent is yet another. All these layers can be removed as the text becomes alive." Mitchell also points out that the process of removing the layers takes time, a fact that may often be overlooked by the commissioning agent in assigning translation tasks to translators at MIL.

\subsection{Causes of the challenges}

a) Going straight to translation before reading through the whole document

A number of translators at MIL start translating right away without having read through the source text first so as to get the general idea of the meaning of the text. This poses a big challenge in the translation process. Mitchell argues that "reading as an essential skill for translation is taken for granted. Translators tend to do everything at the same time, only gradually getting to grips with the message"(90). The end product may be correct, but the process is a matter of trial and error which is time consuming and frustrating (Mitchell 90). Going straight to translation may lead to producing translations out of context or may result in mediocre or incomprehensible outputs. This may emanate from focusing on finding equivalents for individual words instead of the semantics or the meaning of words in a given context. Karamanian says that "translation studies are concerned with a web of relationships, the importance of individual items being decided by their relevance within the larger context"(n.p.). Mitchell notes that "too many wouldbe translators waste time in a hit-and-miss fashion, attempting to piece together the jigsaw puzzle without looking at the picture on the lid" (101). This practice is evident at MIL where a good number of translators immediately begin a translation without engaging in visual thinking, which would otherwise enable them to generate a coherent and fluid text in the target language. It is argued that "when translators read the source text effectively, they produce a better translation in less time because they make the source text come alive while reading" (Mitchell 89).

\section{b) Lack of proper training in translation}

The lack of proper training and a well-established program to train translators is one of the major causes of the challenges in translation in a context where the source and target languages are not the first language of the translator. From the data collected for the study, out of the six translators interviewed, only one of them (16.7\%) was formerly trained in translation. 'Principles and theory of translation' is one of the courses in 
French offered at the advanced level at MIL. The course is taught for only one semester and completing it does not really equip students with the required skills and competence to engage in professional translation. Ill-equipped translators lack both the theoretical knowledge about translation and the practical skills and techniques they need to translate well. Lack of proper training may also lead to misinterpretation of the source text, which makes the translation process more difficult, and the situation becomes even worse when translators are translating outside of their own languages. In the opinion of Newmark, "all translation remains a craft requiring a trained skill, continually renewed linguistic and non-linguistic knowledge and a deal of flair and imagination, as well as intelligence and above all common sense" (7). Delisle argues that "the importance of training translators lies not only in the acquisition and command of languages and translation strategies and procedures, but also in specific knowledge areas and, what is equally important, in the profession of translation" (43). Proper training in translation is scarcely existent at MIL and is thus a major source of some of the challenges in the translation process for nonnative speakers.

\section{c) Lack of exposure}

To become a competent translator, one must be exposed to various categories of documents in different fields of specialization. This gives aspiring translators experience and enables them to acquire competence in translation. This kind of exposure barely exists at MIL. Competence is not measured in terms of the quality of work done but by how much work or text can be translated in the shortest time possible. In cases where a translator undertakes research for purposes of being thorough, s/he may end up taking too long working on one translation assignment. This would, consequently, cause him/her to be eliminated from the translators' team due to delayed submission of the translation product. Some translators are only given documents of the same kind chosen from a wide range of documents. This limits their work to a particular category of documents, rendering them competent in only that one field. When such translators are faced with a document from an unfamiliar field, they encounter many challenges that stem from the lack of exposure to other categories of documents.

\subsection{Strategies used to overcome the challenges}

Translators at MIL employ various strategies in order to overcome the challenges they encounter in the translation of documents from French into English. The participants in the study identified the following as some of the strategies they used most often: 
a) Consult native speakers or colleagues

This is usually done in cases where the words used in the source language text are not found in the existing dictionaries and are culture-bound. One of the participants said that:

Sometimes it may be necessary to ask a native speaker about the meaning of a particular word. Native speakers also help explain meanings of words that have not been covered by bilingual dictionaries.

Consulting native speakers facilitates the translator's work and helps him/her widen his/her vocabulary in the field(s) in which the text is embedded as well as to become sensitized to specific culture-bound expressions or words.

\section{b) Refer to specialized dictionaries}

Enani observes that "the commonly heard advice to translators is 'if you don't know the meaning of a word, look it up in the dictionary.' It is the commonest and the vaguest insofar as the definite article suggests that the dictionary is known to both speaker and listener" (qtd. in Antar n.p.) There are various kinds of dictionaries (bilingual, monolingual, technical dictionaries among others) but the choice of the most appropriate dictionary depends on the style of the source text and the different types of users of the translation. Calderaro indicates two major users of the metatext (text after translation) who may use the translated version: the specialist user and the lay user (n.p.). Antar argues that "identifying the prospective users of the metatext determines which kind of dictionaries the translator will refer to, which level of information should be presented and to detect the exact moments when it is necessary to establish a balance between the scientific level of the author and the knowledge the user supposedly has"(n. p.). According to the participants in the study, referring to specialized dictionaries does not only enable them to find the adequate equivalences for concepts or words whose translation is challenging but also enables them to familiarize themselves with the text as well as acquire knowledge about the technical fields and domains to which the documents may belong.

c) By reading

A copy of every document translated at MIL is made and kept in the records for future reference. When translators are faced with documents from various fields in which they may have limited knowledge, they can first refer to the already translated 
documents. This helps them to learn more about the field of a particular document and also facilitates the translation task.

d) Submitting the translated text for proofreading by a specialized person

Submitting the translated work to a specialist in a given field helps in eliminating errors, crosschecking the terminologies as well as putting the text in the proper jargon or language of a specific community of practice, e.g. medical and juridical, among other fields. This practice also helps greatly in ensuring the quality and correctness of the translated text. This kind of consultation or proof-reading is usually done for medical documents whose mistranslation may be a matter of life or death.

\subsection{Recommendations}

\section{a) Creation of a translators' guild}

Given the increasing demand for translation in Uganda and in the East African region in general and at MIL in particular, there is a need to create a body or a forum that would register, assess competencies, and certify translators, then evaluate and monitor the work they do. Such a forum or body would set standards, monitor performance and ensure the good quality of translated work.

\section{b) Better training of translators}

The theory and practice of translation is currently one of the courses offered for one semester to students of French at the advanced level. The basics of translation theory and practice are covered, but attending the course does not automatically qualify a student to become a competent translator. In spite of the fact that translation activities have been going on at MIL for over fifteen years, there is still no well-established program that focuses on the training of professional translators. Baker encourages formal academic training of translators through which they gain a thorough understanding of various aspects of their work. She also claims that "throughout its long history, translation has never really enjoyed the kind of recognition and respect that other professions such as medicine and engineering enjoy"(2-4). Due to the lack of a wellestablished program in translation at MIL and the high demand for translators and interpreters during regional and international conferences, some Ugandan teachers of French have, in the recent past, pursued further studies in translation and interpretation in France. 
Additionally, translators need training in revision both to review their own work and to perform the revision function for others. Sager defines revision as "the process of control of document production for accuracy, completeness, stylistic appropriateness and the necessary modifications of the translation product" (238).He locates this definition within the larger concept of text modification which includes correction, editing and derivation. According to Giles, revision is "the inspection and correction of a translation by a reviser after the translator has completed the task" (111). Hine states that the essential skill in text revision is to identify three types of errors: "poor writing, non-native writing and poor translation" (139). The level of errors by non-native translators at MIL is evidence that little text revision occurs.

\section{c) Refresher courses in translation}

Refresher courses are necessary at the Institute in order to equip all potential translators with better translation skills and techniques, knowledge about the theory and practice of translation and awareness of the challenges they may encounter in the process of translation. The refresher courses should be offered in the form of short training programs organized by the Institute for its staff and conducted by a professional translator. The training opportunities could also be made accessible to the public; for example for freelance translators to enable them to train and become professional translators, which would consequently contribute to the improvement of the quality and standards of translation.

\section{d) Reading widely}

Reading should not only be restricted to the area(s) of one's expertise since translators are faced with the task of translating a variety of documents from different domains. In order to produce a good translated text, it is recommended that translators read widely in order to keep themselves abreast of knowledge and terminologies used in different fields like environment, health, and politics among others. In addition to reading a variety of documents from different fields, reading as a skill in particular plays a vital role when a translator first encounters a text (Mitchell 90). The benefit of effective reading is that it gives one a blueprint of the text from which to work with confidence (Mitchell 100). To emphasize the importance of reading a text before translation, Brisset points out that:

Traduire un texte exige d'abord qu'on sache lire. Cette lecture peut être intuitive, ou bien, elle peut être se fonder sur une analyse qui fait intervenir un ensemble de concepts et des procédures de traduction. Et d'abord, de lui apprendre à les nommer, 
comme n'importe quel technicien apprend le nom de ses outils et des opérations qu'il effectue. (qtd. in Delisle 52)

This simply means that "translation requires one to know how to read. Reading can be intuitive or analytical. This analysis involves a number of concepts and translation procedures. One ought to, first of all, learn how to name their tools, as a technician learns his and the tasks he performs".

\subsection{Conclusion and suggestion for further research}

The translation that occurs at MIL is based on the faulty premise that one is a competent translator if one is a qualified foreign language teacher. In fact, Delisle states that "competence in translation does not only mean having sound linguistic knowledge of both the source language and target language but one should also have reading comprehension ability, the knowledge of specialized fields, cultural knowledge and should be able to handle strategic and tactical tools for a good translating performance"(43), hence "the importance of a didactic translation approach; a methodology that allows the development of an effective and efficient transfer process from one language to another" (Delisle 112). The challenges a non-native translator faces at MIL are a result of the manner in which foreign language teachers become translators without undergoing proper training. As Baker suggests, "translators need to develop an ability to stand back and reflect on what they do and how they do it" (4). Translators at MIL assume three roles: the translator, proof-reader/reviser and quality controller. Ideally, any translation should be undertaken by at least two people: the translator and the reviser. To the best of my knowledge, this does not happen in the current practice of translation at MIL and it is unlikely that this practice would be introduced in an environment where the overriding motive for translating is to make "quick" money. This pushes some of the colleagues who translate to "personalize" and dominate the translation exercise. Consequently, work accumulates, which makes them look for equivalents of individual words instead of focusing on the coherence of the translation product. Baker argues that "coherence is a network of conceptual relations which underlie the surface of the text"(218). To the commissioning agent (the person who acts as the intermediary between the client and the translator and designates translation tasks to translators) and some translators at MIL, the motive of translation seems to be "earning as much money as quickly as possible" at the expense of the quality of the translation product. It would be a wise idea for non-native translators at MIL to change their approach to translation and the manner in which they undertake the translation exercise. 
It would also be important for the commissioning agent as well as the non-native translators at MIL to consider Mitchell's position in relation to translation activities rather than looking at translation as only a source of extra income or business, which is guided and driven by tight deadlines. This approach would enable translators to work in such a way that they are more committed to minimizing the occurrence of mistakes as obvious as the ones mentioned in Section 2.5 above.

More research needs to be carried out in the area of training of translators as well as on the specific issues and challenges related to the translation of documents by nonnative speakers of the languages in which they work. This research would help in the training of translators as well as in setting and maintenance of standards in translation. 


\section{REFERENCES}

Antar, S. Abdellah. "What Every Novice Translator Should Know." Translation Journal 6.3 (2002). Web, July 2002.

Baker, Mona. In Other Words: A Course Book in Translation. London: Routledge, 1992.

Ballard, Michel. Le commentaire de traduction anglaise. Paris: Nathan, 1992.

Bassnett, Susan. Translation Studies. Revised Edition. London: Routledge, 1991.

Booth, Philip. "The Cultural Dimension in Comparative Research: Making Sense of Development Control in France.” European Planning Studies. 1.2 (1993): 217-229.

Calderaro, Lic Denis C. “Considerations on Teaching Translation.” Translation Journal 2.3 (1998). Web, July 1998.

Casanave, P. Christine. "Transitions: The Balancing Act of Bilingual Academics.” Journal of Second Language Writing 7.2 (1998): 175-203.

Crane, L. G. M. B. Lombard \& E. M. Tenz, "More than Just Translation: Challenges and Opportunities in Translingual Research." Social Geography 4 (2009): 39-46. Web. July 2011.

Delisle, Jean. L'Analyse du discours comme méthode de traduction. Cahiers de traductologie. 2nd ed. Ottawa: Editions de l'Université d'Ottawa, 1980.

Delisle, Jean. La traduction raisonnée. Les Presses de l’Université d’Ottawa, 1993.

Gile, Daniel. "Basic Concepts and Models for Interpretation and Translation Training." Benjamins Translation Library 8. Amsterdam/Philadelphia: John Benjamins, 1995.

Hine, T. Jonathan. "Teaching Text Revision in a Multilingual Environment." Beyond the Ivory Tower 12 (2003): 135-156.

Jakobson, Roman."On linguistic aspects of translation." Selected Writings II: Word and Language. The Hague/Paris: Monton, 1971. 260-266.

Karamanian, A. Patricia. 2001. "Translation and Culture." Translation Journal 6.1 (2002) Web. January 2002. 
Lustig, W. Myron \& Jolene Koester. Intercultural Competence: Interpersonal Communication Across Cultures. New York: Harper-Collins, 2010.

Mitchell, Florence. "Reading, an Essential Skill for Professional Translators." Teaching Translation in Universities: Present and Future Perspectives. London: CILT, 1996.

Newmark, Peter. A Textbook of Translation. London: Prentice Hall, 1998.

Sager, C. Juan. Language Engineering and Translation: Consequences of Automation.

Benjamins Translation Library 1. Amsterdam/Philadephia: John Benjamins. 1994.

Sewell, Penelope. \& Higgins, Ian. (Eds). Teaching Translation in Universities: Present and Future Perspectives. London: CILT, 1996.

Thriveni, C. "Cultural Elements in Translation: The Indian Perspective." Translation Journal 6.1 (2002). Web. January 2002. 